\title{
İnguinal herni hastalarında açık mı kapalı teknik mi daha fazla stres yaratır?
}

\author{
Which operative technique is associated with higher levels of stress at inguinal hernia \\ patients?
}

\author{
Feridun Suat Gökçe, İrfan Coşkun
}

Gönderilme tarihi:11.07.2018

Kabul tarihi:28.11.2018

\section{Özet}

Amaç: İnguinal herni her iki cinste, tüm ırklarda, her yaşta sık görülen bir hastalıktır ve tedavisi cerrahidir. Cerrahi girişimlerde ana gayelerden biri travmayı en aza indirmektir. Çalışmamızda laparoskopik (Laparoskopik total ekstraperitoneal teknik) ve açık (Lichtenstein tekniği) inguinal herni ameliyatlarında travma ve strese cevabı yansıtabilecek bazı kan parametrelerini ameliyat öncesi ve sonrası ölçerek bu iki ameliyat tekniği arasında hastaların maruz kaldığı travma düzeylerinin ve insizyon boyutunun farklılık gösterip göstermediğini saptamayı amaçladık.

Gereç ve Yöntem: Randomize çalışmada kliniğimizde inguinal herni tanısı konulan 40 hastanın 20'sine laparoskopik total ekstraperitoneal tekniğiyle, diğer 20 hastaya da açık teknikle greftli herni onarımı ameliyatı yapıldı. Çalışmaya alınan olgularda ameliyat öncesi, ameliyat sırasında, ameliyat sonrası ikinci ve yirmi dördüncü saatlerde antekubital venöz kan alındı. Kanda growth hormon, kortizol ve malonildialdehit düzeylerine bakıldı. Bulgular: Grupların; yaş cinsiyet ve vücut kitle indeksleri arasında istatistiksel fark saptanmadı ( $p=0.78$, $p=0.429, p=0.616$ ). İnsizyon boyutu laparoskopik yöntemde istatistiksel açıdan anlamlı ölçüde küçük çıktı $(p<0,001)$. Growth hormon düzeyleri her iki teknikte de peroperatif yükselirken, postoperatif 2 . saatte açık teknikle yükselme devam etti fakat laparoskopik yöntemle anlamlı düşüş saptandı $(p=0.005)$. Kortizol değerleri her iki ameliyatta preoperatif anlamlı olarak yüksek saptanırken laparoskopik teknikte postoperatif 2 . saatte $(p=0.07)$, açık teknikte postoperatif 24 . saatte $(p=0.006)$ anlamlı düşme saptandı. Malonildialdehit değerleri arasında preoperatif, peroperatif, postoperatif 2 ve 24. saatler arasında anlamlı farklılık yoktu. Fakat her iki teknik karşılaştırıldığında açık teknikte malonilaldehit değeri anlamlı olarak yüksek saptandı $(p=0.038)$.

Sonuç: İnguinal herni ameliyatları için laparoskopik yaklaşım günümüzde altın standart olarak kabul edilmemektedir. Çalışmamızda, laparoskopik girişimlerde, açık ameliyatlara göre sınırlı da olsa stres ve cerrahi travma daha düşük gözükmektedir. Bununla birlikte cerrahi yöntem seçiminde hastanın genel durumu ve tercihi ile cerrahın tercihinin daha önemli olduğu düşüncesindeyiz.

Anahtar kelimeler: İnguinal herni, laparoskopik herni onarımı, greftli açık herni onarımı, stres hormonları.

Gökçe FS, Coşkun İ. İnguinal herni hastalarında açık mı kapalı teknik mi daha fazla stres yaratır ? Pam Tıp Derg 2019;12:55-59.

\footnotetext{
Abstract

Purpose: Inguinal hernia is a prevalent condition among people of every sex, age and race and the treatment is surgery (1). One of the main goals during the surgery is to minimize surgical trauma. In this study, we aimed at finding out whether the intensity of surgical trauma and incision size differ between open inguinal hernia repair surgery and laparoscopic total extraperitoneal inguinal hernia repair surgery by measuring preoperative and postoperative levels of certain blood parameters that might reflect the intensity of trauma and response to trauma.

Materials and Methods: A total of 40 patients who underwent inguinal hernia repair surgery were included in the study. 20 out of 40 patients underwent a laparoscopic total extraperitoneal inguinal hernia repair and 20 underwent open inguinal hernia repair. Blood samples were taken from the antecubital vein before the surgery, during the surgery, at hour 2 and hour 24 after the surgery and blood growth hormone, cortisol and malonyldialdehyde levels were measured.

Results: No intergroup differences were found in age, sex and body mass index $(p=0.78, p=0.429, p=0.616)$. Incision sizes were statistically smaller in laparoscopic technique $(p<0.001)$. Elevated growth hormone levels were detected during the surgery by either technique. Growth hormone levels continued to increase at hour 2 in patients who underwent open surgery while a significant decrease was detected at hour 2 in patients who underwent laparoscopic surgery $(p=0.005)$. Preoperative blood cortisol levels were found to be significantly elevated in both groups and significant reductions were detected at hour 2 after the surgery in patients who underwent laparoscopic repair $(p=0.07)$ while significant reductions were detected in patients who underwent

Feridun Suat Gökçe, Op.Dr. Balıklı Rum Hastanesi Genel Cerrahi Kliniği, ISTANBUL, e-posta:fsgokce70@hotmail.com (orcid.org/0000-00018597-5787) (Sorumlu yazar)

İrfan Coşkun, Prof.Dr. Trakya Üniversitesi Tıp Fakültesi Genel Cerrahi Kliniği, EDİRNE, e-posta: irfancoskun@hotmail.com (orcid.org/00000003-2963-0519)
} 
open repair at hour 24 after the surgery $(p=0.006)$. No significant differences were detected among blood malonyldialdehyde concentrations measured before the surgery, during the surgery and at hour 2 and hour 24 after the surgery. However intergroup comparisons revealed that blood malonyldialdehyde concentrations were significantly higher in the open surgery group $(p=0.038)$.

Conclusion: Although laparoscopic surgery is not considered a gold standard for inguinal hernia repair, this approach may be the surgery of choice for inguinal hernia repair, particularly in cases of recurrent and bilateral inguinal hernia, as this technique is associated with lower levels of stress and trauma.

Key words: Inguinal hernia, laparoscopic hernia repair, grafted open hernia repair, stress hormones.

Gökçe FS, Coşkun İ. Which operative technique is associated with higher levels of stress at inguinal hernia patients? Pam Med J 2019;12:55-59.

\section{Giriş}

Inguinal herni her iki cinste, tüm ırklarda, her yaşta sık görülen bir hastalıktır ve tedavisi cerrahidir(1). Cerrahi girişimlerde ana gayelerden birisi travmayı en aza indirmektir. İnguinal herni ameliyatlarında günümüzde açık teknik (konvansiyonel) ve laparoskopik teknikler uygulanmaktadır. Laparoskopik olarak intraperitoneal onlay mesh tekniği (IPOM), trans abdominal preperitoneal (TAPP) ve ekstraperitoneal (TEP) onarımlar yapılabilir. Çalışmamızda laparoskopik olarak TEP yöntemini uyguladık. TEP yönteminde ekstraperitoneal olarak girilip fitık kesesi serbestleştirildikten sonra mesh fitık bölgesine kas ve periton arasına yerleştirilir. Açık inguinal herni onarımında ise Bassini, Shouldice, Lichtenstein onarımı gibi çok çeşitli teknikler vardır. Açık teknikte Lichtenstein prosedürünü tercih ettik. Bu teknikte fıtık kesesi serbestleştirildikten sonra high ligasyon ve/ veya fıtık imbrikasyonu yapılıp mesh, gerginlik oluşturmayacak şekilde kas üstüne tespit edilir. Travma alanından kalkan afferent uyarıların hipotalamusu uyarması sonucu salgılanan faktörler hipofizi uyarır ve buradan en başta growth hormon $(\mathrm{GH})$ salgılanır. Fiziksel ve nörojenik streslerin hemen her tipi ön hipofizden hızla GH salgılanmasına neden olur [2]. Travma sonrası kortizol miktarı travmanın şiddetine göre artış gösterir [3]. Travma sonucu oluşan hücresel zedelenme, serbest radikallerin oluşumunu arttırır. Antioksidan bir enzim olan malonilaldehit (MDA) düzeyi oksidatif stresin bir göstergesi olarak bilinmektedir [4, 5]. MDA diğer streslerde artış gösterdiği gibi ameliyatın oluşturduğu streste de kanda düzeyi artış gösteren bir parametredir. Çalışmamızda laparoskopik total ekstraperitoneal ve açık greftli inguinal herni ameliyatlarında travma ve strese cevabı yansitabilecek MDA, GH ve kortizol değerlerini ameliyat öncesi ve sonrası ölçerek iki ameliyat türü arasında hastaların maruz kaldığı travmanın, farklıık gösterip göstermediğini saptamayı ve insizyon boyutlarını karşılaştırmayı amaçladık.

\section{Gereç ve yöntem}

$\mathrm{Bu}$ çalışma, insanlar üzerinde yapılan biyomedikal araştırmaları düzenleyen Helsinki Bildirgesi'nin önerilerine uygun olarak yapılmıştır. Bu prospektif ve randomize klinik çalışmanın etik kurul onayını alınmıştır (KAEK50 Karar No:1281). Tüm hastalara ameliyat öncesi detaylı bilgi verilmiş ve yazılı onam formu alınmıştır.

Bu çalışma elektif laparoskopik TEP ve açık greftli inguinal herni onarımı yapılan yetişkin hasta grubunda yapıldı. Çalışmaya alınma kriterleri olarak; [1] Anestezi muayenesinde Amerikan Anesteziyoloji Derneği skorunun (ASA) 1 ve 2 kategorisinde olması ve [2]. tek taraflı inguinal fitık olması olarak belirlendi. Çalışmadan dışlanma kriterleri [1] nüks veya bilateral inguinal herni olması; [2] inkarsere veya strangüle herni olması; [3] bilinen hipertansiyon, diyabetes mellitus, asit, bağ dokusu hastalığı, kalp / böbrek yetmezliği ve hipoalbüminemi olması; vücut kitle indeksinin 30 veya üzerinde olması ve [4] aspirin veya diğer kan incelticiler veya antikoagülanların kullanımı olarak belirlendi.

Kliniğimize inguinal herni tanısıyla başvuran 40 hasta, randomize olarak, sırasıyla 2 gruba ayrıldı. Hastaların 20'sine laparoskopik total ekstraperitoneal (TEP) tekniğiyle, diğer 20 hastaya da açık teknikle herni operasyonu yapıldı İnguinal herni onarımı laparoskopik olarak yapılan olgular grup 1 , açık olarak onarım yapılan grup ise grup 2 olarak çalışmaya alındı. Çalışmaya alınan olgulardan operasyon öncesi, operasyon sırasında, operasyon sonrası ikincive yirmi dördüncü saatlerde antekubital venöz kan 
alındı. Kanda $\mathrm{GH}$, kortizol ve MDA düzeylerine bakıldı. GH ile kortizol immulite cihazıyla ve kimyasal immunoassey yöntemiyle çalışıldı. Bu ölçüm sekiz kez tekrarlanıp, hesaplandı. MDA düzeyi tiobarbitürik asit yöntemi ile Slater TF metoduna göre manuel olarak ölçüldü. Tüm olgular operasyon günü hastaneye yatırıldı, operasyonlar elektif şartlar altında, genel anestezi altında yapıldı, ameliyatlar sabah ilk vaka olarak alındı ve ameliyat sonrası ilk gün taburcu edildi.

\section{İstatistiksel analiz}

İstatistiksel Analiz Veriler SPSS (Statistical Package for Social Sciences, Windows, sürüm 22.0) programı ile analiz edildi. Sürekli değişkenler ortalama ve standart dağılım olarak belirtildi. Normal dağılım gösterip göstermemesine göre Student's $t$ test veya Mann-Whitney U-test'i kullanılarak sürekli değişkenler gruplar arasında karşılaştırıldı. İstatistiksel olarak $p<0,05$ değeri anlamlı olarak kabul edildi. Power analizde iki grup ortalaması arasında 1.00 birimlik fark anlamlı kabul edildiğinde her grupta en az 18 olgunun olması gerektiği saptandı. Çalışmamızda her grup için 20 olgu çalışmaya alındı. Tip 1 hata 0,05 , testin gücü 0,80 olarak hesaplandı.

\section{Bulgular}

Grup 1'deki TEP tekniği yapılan hastaların yaş ortalaması 39,6, Grup 2'deki açık fıtık onarımı yapılan hastaların yaş ortalaması 37,3 idi ( $p=0.78)$. Grup1'de 20 hastanın beşi, Grup 2'de 20 hastanın üçü kadındı ve gruplar arasında cinsiyet açısından istatistiksel fark saptanmadı $(p=0.429)$. Grup 1'de VKI ortalaması 25,3, Grup 2'de 24,9 du ve iki grup arasında istatistiksel fark saptanmadı $(p=0.616)$. $\mathrm{GH}$, TEP operasyonunda peroperatif anlamlı olarak yükselirken $(p=0.026)$, postoperatif 2 . saatte anlamlı düşme gösterdi $(p=0.005)$. Fakat açık ameliyat sırasındaki peroperatif yükselme $(p=0.015)$, postoperatif 2 . saatte de devam etti ve ancak 24. saatte düştü $(p=0.043)$. Açık operasyonların postoperatif 2 . saatteki değerleri TEP'e göre anlamlı olarak daha yüksekti $(p=0.009)$, (Tablo 1).

Kortizol değerleri her iki ameliyatta preoperatif anlamlı olarak yükselirken (Grup $1 p=0.044$, Grup $2 p=0.02$ ) laparoskopik ameliyatta postoperatif 2 . saatte anlamlı olarak düştü ( $p=0.07)$. Açık ameliyatta ise postoperatif 24. saatte anlamlı düşme gözlendi $(p=0,006)$ ve iki grup arasında anlamlı farklılık saptanmadı $(p>0,05)$ (Tablo 2).

MDA değeri için preoperatif, peroperatif, postoperatif 2. ve 24. saatler arasında anlamlı farklılık yoktu $(p>0.05)$. Fakat her iki teknik karşılaştırıldığında açık teknikte MDA değeri anlamlı olarak yüksek saptandı $(p=0.038)$, (Tablo 3).

Grup 1'deki insizyon boyutu ortalaması 3.08 \pm 0.61 Grup 2'deki insizyon boyutu ortalaması $6.25 \pm 1.20$. Her iki teknikteki insizyon boyutu karşılaştırıldığında laparoskopik yöntemde istatistiksel olarak anlamlı olarak küçük saptandı $(p<0.001)$.

Tablo 1. Laparoskopik ve açık operasyonlarda growth hormon değerlerindeki değişimler

\begin{tabular}{lllll}
\hline Grup 1 & $\begin{array}{l}\text { ORTALAMA } \\
(\mathrm{ng} / \mathrm{ml})\end{array}$ & $\begin{array}{l}\text { Standart Sapma } \\
( \pm)\end{array}$ & $\begin{array}{l}\text { Minimum } \\
(\mathrm{ng} / \mathrm{ml})\end{array}$ & $\begin{array}{l}\text { Maksimum } \\
(\mathrm{ng} / \mathrm{ml})\end{array}$ \\
\hline Preoperatif & 0,55 & 0,66 & 0,05 & 2,50 \\
Peroperatif & 5,94 & 9,78 & 0,14 & 40,00 \\
Postoperatif 2. saat & 1,59 & 1,84 & 0,01 & 6,00 \\
Postoperatif 24. saat & 1,87 & 2,67 & 0,06 & 9,50 \\
Total & 2,49 & 5,47 & 0,01 & 40,00 \\
\hline Grup 2 & ORTALAMA & Standart Sapma & Minimum & Maksimum \\
& $(\mathrm{ng} / \mathrm{ml})$ & $( \pm)$ & $(\mathrm{ng} / \mathrm{ml})$ & $(\mathrm{ng} / \mathrm{ml})$ \\
Preoperatif & 0,42 & 0,63 & 0,05 & 2,40 \\
Peroperatif & 7,48 & 9,38 & 0,05 & 27,90 \\
Postoperatif 2. saat & 5,74 & 6,18 & 0,06 & 21,10 \\
Postoperatif 24. saat & 1,89 & 3,75 & 0,05 & 16,10 \\
Total & 3,88 & 6,48 & 0,05 & 27,90 \\
\hline
\end{tabular}


Tablo 2. Laparoskopik ve açık operasyonlarda kortizol değerlerindeki değişimler

\begin{tabular}{lllll}
\hline Grup 1 & $\begin{array}{l}\text { ORTALAMA } \\
(\mu \mathrm{g} / \mathrm{dl})\end{array}$ & $\begin{array}{l}\text { Standart Sapma } \\
( \pm)\end{array}$ & $\begin{array}{l}\text { Minimum } \\
(\mu \mathrm{g} / \mathrm{dl})\end{array}$ & $\begin{array}{l}\text { Maksimum } \\
(\mu \mathrm{g} / \mathrm{dl})\end{array}$ \\
\hline Preoperatif & 13,63 & 5,91 & 2,20 & 23,30 \\
Peroperatif & 20,93 & 8,82 & 7,50 & 32,90 \\
Postoperatif 2. saat & 12,55 & 5,36 & 5,30 & 22,00 \\
Postoperatif 24. saat & 15,28 & 7,65 & 4,40 & 37,00 \\
Total & 15,59 & 7,66 & 2,20 & 37,00 \\
\hline Grup 2 & ORTALAMA & Standart Sapma & Minimum & Maksimum \\
& $(\mu \mathrm{g} / \mathrm{dl})$ & $( \pm)$ & $(\mu \mathrm{g} / \mathrm{dl})$ & $(\mu \mathrm{g} / \mathrm{dl})$ \\
Preoperatif & 11,99 & 5,71 & 2,10 & 30,20 \\
Peroperatif & 17,99 & 7,89 & 3,60 & 31,20 \\
Postoperatif 2. saat & 15,74 & 6,68 & 2,70 & 30,80 \\
Postoperatif 24. saat & 11,95 & 5,02 & 2,40 & 18,00 \\
Total & 14,42 & 6,81 & 2,10 & 31,20 \\
\hline
\end{tabular}

Tablo 3. Laparoskopik ve açık operasyonlarda malonilaldehit değerlerindeki değişimler

\begin{tabular}{lllll}
\hline Grup 1 & $\begin{array}{l}\text { ORTALAMA } \\
(\mathrm{mmol} / \mathrm{l})\end{array}$ & $\begin{array}{l}\text { Standart Sapma } \\
( \pm)\end{array}$ & $\begin{array}{l}\text { Minimum } \\
(\mathrm{mmol} / \mathrm{l})\end{array}$ & $\begin{array}{l}\text { Maksimum } \\
(\mathrm{mmol} / \mathrm{l})\end{array}$ \\
\hline Preoperatif & 0,03 & 0,02 & 0,00 & 0,08 \\
Peroperatif & 0,06 & 0,04 & 0,00 & 0,13 \\
Postoperatif 2. saat & 0,08 & 0,13 & 0,01 & 0,63 \\
Postoperatif 24. saat & 0,04 & 0,03 & 0,00 & 0,12 \\
Total & 0,05 & 0,07 & 0,00 & 0,63 \\
\hline Grup 2 & ORTALAMA & Standart Sapma & Minimum & Maksimum \\
& $(\mathrm{mmol} / \mathrm{l})$ & $( \pm)$ & $(\mathrm{mmol} / \mathrm{l})$ & $(\mathrm{mmol} / \mathrm{l})$ \\
Preoperatif & 0,05 & 0,05 & 0,00 & 0,18 \\
Peroperatif & 0,05 & 0,05 & 0,00 & 0,14 \\
Postoperatif 2. saat & 0,05 & 0,05 & 0,00 & 0,15 \\
Postoperatif 24. saat & 0,06 & 0,05 & 0,00 & 0,17 \\
Total & 0,05 & 0,05 & 0,00 & 0,18 \\
\hline
\end{tabular}

\section{Tartışma}

Cerrahi travmaya vücudun refleks nöroendokrin yanıtı üç değişik yolla olur; otonom yanit, hormonal yanit ve lokal doku yanıtı. Cerrahi travmanın şiddeti ve oluşturduğu inflamasyonun derecesi ile vücutta ortaya çıkan bu cevapların fazlalığı arasında ilişki vardır. Laparoskopik girişimlerin açık girişimlere oranlara daha az invaziv olduğu ve daha az şiddette doku yaralanması yaptığından dolayı vücutta oluşturduğu reaksiyonların daha az olacağını bildiren çalışmalar mevcuttur [6]. Cilt kesisiyle öncelikle nöroendokrin cevap oluşur ve kortizol artar [7]. Çalışmamızda kortizol değerlerinde iki grup arasında anlamlı fark bulunamadı ancak peroperatif yükselen değerler laparoskopik grupta postoperatif 2 . saatte anlamlı olarak düştü, buna karşıık açık grupta anlamlı düşme postoperatif 24. saatte oldu. Çalışmamızda $\mathrm{GH}$ değeri postoperatif 2. saatte TEP yapılan hastalarda açık tekniğe göre anlamlı düşüş saptandı. Travma sonucu oluşan hücresel zedelenme, serbest radikallerin oluşumunu arttırır [8]. MDA düzeyi, oksidatif stresin bir göstergesi olarak bilinmektedir [4, 5, 9]. Gal ve arkadaşlarının çalışmasında postoperatif erken dönemde MDA değerleri laparoskopik 
grupta anlamlı olarak düşük bulunmuştur [4]. Çalışmamızda ise gruplar içinde MDA değerleri açısından anlamlı farklılık bulunmamakla birlikte postoperatif 24. saatteki değerler literatürle uyumlu olarak açık operasyonlarda anlamlı olarak daha yüksekti. Laparoskopik ve açık operasyonları karşılaştırırken cerrahi travmanın vücutta oluşturduğu cevapta sadece operasyon yönteminin değil; hastanın oksijen dengesi, fiziksel aktivitesi, beslenmesi, ağrı ve psikolojik durumunun da etkili olabileceği unutulmamalıdır [10]. Çalışmamızda stres göstergesi olarak kullandığımız parametrelerde her iki operasyon türünde de ameliyat öncesine göre ameliyat sırasında anlamlı yükselme oldu. Sonuçlar bize laparoskopik operasyonlarda da travmaya bağlı doku hasarı olduğunu ancak bu hasarın açık operasyonlarda gözlenenden nispeten daha az olduğunu düşündürmektedir. Bu sonuçlarla inguinal herni operasyonlarında TEP tekniğinin açık tekniğe göre daha az travma oluşturan bir yöntem olarak uygulanabileceği söylenebilir. Çift taraflı fıtık hastalarında laparoskopik yapılacaksa trokar yerleri ve sayısı tek taraflıyla aynı şekilde açılır yani açık teknikte olduğu gibi farklı insizyonlar yapılmaz.

İnguinal herni ameliyatları için laparoskopik yaklaşım günümüzde altın standart olarak kabul edilmemektedir. Çalışmamızda, laparoskopik girişimlerde, açık ameliyatlara göre sınırlı da olsa stres ve cerrahi travma daha düşük gözükmektedir. Bununla birlikte cerrahi yöntem seçiminde hastanın genel durumu ve tercihi ile cerrahın tercihinin daha önemli olduğu düşüncesindeyiz.

Çıkar İlişkisi: Yazarlar çıkar ilişkisi olmadığını beyan eder.

\section{Kaynaklar}

1. Öberg S, Andresen K, Rosenberg J. Etiology of inguinal hernias: a comprehensive review. Front Surg 2017;22:52.

2. Roser P, Wehrhahn T, Krogmann H, Riedel N, Marshall RP, Gille J, Flitsch J, Aberle J. Somatotrope pituitary function in professional soccer players. Exp Clin Endocrinol Diabetes 2018;126:306-308.

3. Şimşek Ş, Kaplan I, Uysal C, Yüksel T, Alaca R. The levels of cortisol, Oxidative stress, and DNA damage in the victims of childhood sexual abuse: a preliminary study. J Child Sex Abus 2016;25:175-184.
4. Cao Z, Chen L, Liu Y, Peng T. Oxysophoridine rescues spinal cord injury via anti-inflammatory, anti-oxidative stress and anti-apoptosis effects. Mol Med Rep 2018; 17:2523-2528.

5. $\mathrm{Xu} \mathrm{YJ,} \mathrm{Yu} \mathrm{ZQ,} \mathrm{Zhang} \mathrm{CL,} \mathrm{et} \mathrm{al.} \mathrm{Protective} \mathrm{effects} \mathrm{of}$ ginsenosides on 17[formula: see text]- ethynyelstradiolInduced Intrahepatic cholestasis via anti-oxidative and anti-Inflammatory mechanisms in rats. Am J Chin Med 2017;45:1613-1629.

6. Karayiannakis AJ, Makri GG, Mantzioka A Karousos D, Karatzas G. Systemic stress response cholecystectomy: a randomized trial. Br J Surg 1997;84:467-471.

7. Naito $Y$, Tamai $S$, Shingu $K$, et al. Responses of plasma adrenocorticotropic hormone, cortisol and cytokines during and after upper abdominal surgery. Anesthesiology 1992;77:426-431.

8. Halwell B. Reactive oxygen species in living systems: source, biochemisy and role in human disease. Am J Med 1991;91:14-22.

9. Timerbaev VKH, Kontarev SI, Mil'chakov VI, et al. Lipid Peroxidation processes in the blood of patients during thoracic surgery. Anesthesiol Reanimatol 1993;6:1820.

10. Redmond HP, Watson RWG, Houghton T, Condron C, Watson RGK, Bouchier Hayes D. Immune function in patients undergoing open vs laparoscopic cholecystectomy. Arch Surg 1994;129:1240-1246. 